\title{
Synthesis of Novel Heteropolycyclic Nitrogen Systems Bearing Fluorine Substituted Pyrazolo[3,4-d] Pyrimidine Derived from Polyfunctional $\pi$-Acceptor Compounds and Guanidine as Fungicidal Probes
}

\author{
Dina A. Bakhotmah, Salwa Y. Al-Hazme* \\ Department of Chemistry, Faculty of Science, King Abdulaziz University, Jeddah, Saudi Arabia \\ Email: *s.y.alhelali@gmail.com
}

How to cite this paper: Bakhotmah, D.A. and Al-Hazme, S.Y. (2019) Synthesis of Novel Heteropolycyclic Nitrogen Systems Bearing Fluorine Substituted Pyrazolo[3,4-d] Pyrimidine Derived from Polyfunctional $\pi$-Acceptor Compounds and Guanidine as Fungicidal Probes. International Journal of Organic Chemistry, 9, 73-83.

https://doi.org/10.4236/ijoc.2019.91007

Received: February 17, 2019

Accepted: March 25, 2019

Published: March 28, 2019

Copyright $\odot 2019$ by author(s) and Scientific Research Publishing Inc. This work is licensed under the Creative Commons Attribution International License (CC BY 4.0).

http://creativecommons.org/licenses/by/4.0/

\begin{abstract}
Novel heteropolycyclic nitrogen systems bearing fluorine substituted pyrazolo[3,4- $d]$ pyrimidine moiety have been synthesis by the interaction between $N$-heteroaryl guanidine 4 with polyfunctional $\pi$-acceptors in different media and condition. The structures of the synthesis compounds were established by spectroscopic analysis and evaluated as antifungal probes in various concentration.
\end{abstract}

\section{Keywords}

Synthesis Polyheterocyclic, Pyrazolo[3,4-d] Pyrimidine, Antifungal

\section{Introduction}

Recently, functionality substituted fluorinated pyrazolo[3,4- $d$ ] pyrimidine derivative, exhibited a wide spectrum in the biological active fields specially as enzymatic effects on cellobiase activity produced by some fungi [1] [2] [3]. Pyrazolopyrimidine derivatives possess a wide application of the biological activities, which encourage to research in this field, for example, antimicrobial [4], antibacterial [5], antitumor [6], and anticancer [7]. In addition, introduction fluorine atoms to pyrazolopyrimidine enhance and improve their pharmacological properties [8] [9]. Abdel Rahman et al. [10] [11] [12], reported that the orientation of cyclization reactions of functionalized amino and/or hydrazine bearing heterocyclic moieties depends on the effect of substituents, solvent $\mathrm{pH}$, temper- 
ature, chemoselective orientation heterocycleization and regioselectivity of electrocyclization as well as preferring the cite of closure as this work focused on $N$-heteroaryl guanidine 4 as electron donors towards various electron-acceptors reagents in view of their fungicidal effects.

\section{Results and Discussion}

Ortho diamines are active substrates for the building of a new heterocyclic nitrogen system [13]. In the case of unsymmetrical diamines, the substituents influence the initial participation of a particular amino group in the reaction, resulting in chemoselective products. In addition, the more electron withdrawing will be attacked firstly by primary amine [14]. Accordingly, the present work studies the interaction between $N^{p}$-heteroaryl guanidine 4 with various polyelectron withdrawing centers in different media and conditions.

The starting material $N^{p}$-heteroaryl guanidine 4 is obtained from condensation of 4-fluorobenzaledhyed with 4,5-dihydro-1-phenyl-3-methylpyrazol-5-one (1) in reflux EtOH/piperidine followed by cycloaddition via a nucleophilic attack with guanidine $\mathrm{HCl}$ under the same conditions to give 6-amino-4-(4'-fluorophenyl)-1-phenyl-3-methylpyrazolo[3,4-d]pyramidine (3) which upon a simple addition to cyanamide give $N^{p}$-heteroaryl guanidine (4) (Scheme 1).

Interestingly the interaction between compound 4 with 4-nitrobenzoyl isothiocyanate (5) in non-polar solvent as dioxane led [12] give 1-heteroaryl-2-amino6-aryl-1,3,5-triazin-4-thione (6) while some reaction in polar $\mathrm{EtOH} /$ piperidne, resulted in 1-(heteroaryl)-2-imino-4-aryl-1,3,5triazin-6 (SH) thione (7) (Scheme 2).

In addition, the interaction between guanidine derivative 4 and $\pi$-acceptors containing a carbonitrile group (8 and 10) in polar solvent as EtOH/Piperidne the more electronegativity cite will attacked firstly before a moderate electronegativity cite via electrocyclization reaction [12] to give 1-(heteroaryl)-2-imino4-amino-6-aryl-pyrim-idine-5-yl-carbonitrile (9) and/or 1-(heteroaryl)-2-

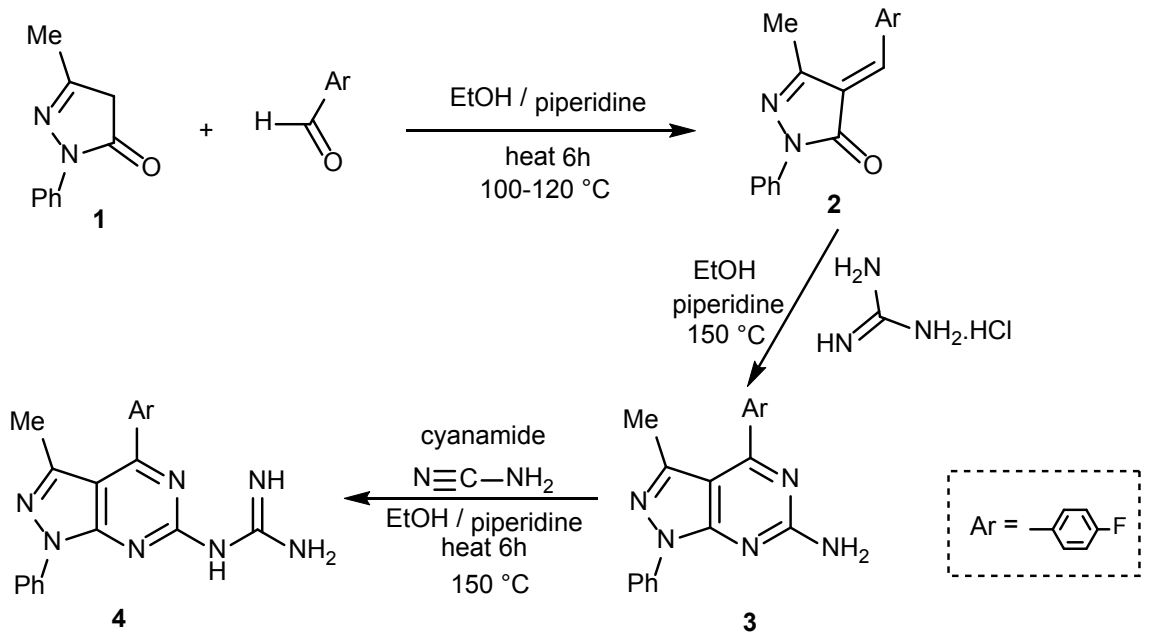

Scheme 1. Synthesis of compounds 2, 3, and 4 . 


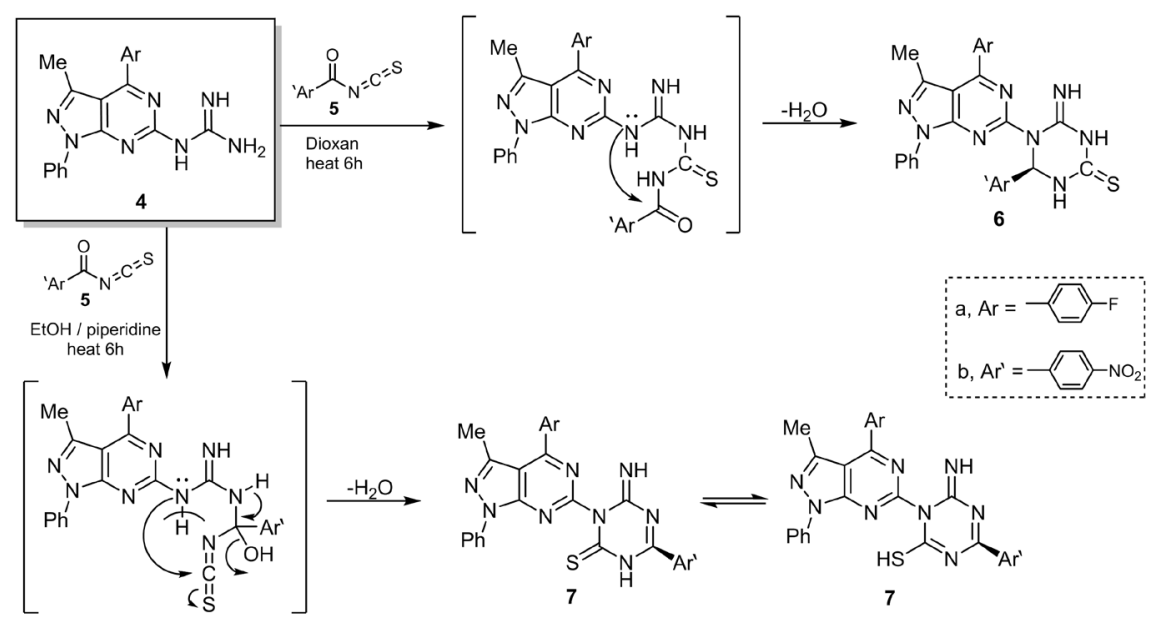

Scheme 2. Synthesis of compounds 6 and 7.

imino-4-amino-6-aryl-pyrimidine-5-carboxylic acid (11) respectively (Scheme 3). Compound 11 gave the acidity test with aqueous $\mathrm{NaHCO}_{3}$.

Cycloaddition reaction of $N$-heteroaryl guanidine 4 with 1-phenyl-3-methyl4-arylidene-pyrazol-5-one (12) in reflux $\mathrm{EtOH} /$ piperidine led to the direct formation of pyrazolopyrimidine derivative 13 via a nucleophilic attack (Scheme 4).

Finally, the introduction of F-atoms to heterocyclic nitrogen systems often improve their physical, chemical and biological properties [15] [16]. Thus, cyclocondensation of $N^{p}$-(heteroaryl) guanidine 4 with fluorinated 1,3-bicarbonyl compounds as hexafluoro acetylacetone (14) in reflux in EtOH, afforded $N$ (heteroaryl)-2-imino-4,6 di(trifluoromethyl)pyrimidine (15) (Scheme 5).

As recently, the synthesis of pyrazolopyrimidine moiety bearing other heterocyclic systems as bioactive semidrugs was reported through a type of nucleophilic attack toward a move positive electrophilic center followed by cycloaddition reaction [1] [2] [17] [18] [19] [20], this investigation was focused on the synthesis of novel fluorine substituted heteropolycyclic nitrogen systems containing a pyrazolopyrimidine moiety in view of their cellobiase activity towards some fungi.

The structure of the products were deduced from correct elemental analysis and their spectral measurements. The reagents used prepared according to Abdel-Rahman et al. [13] [14].

IR absorption spectral study of the obtained systems $6,7,9,11,13$, and 15 give us a good indication about their structural.

IR spectra of compound 6 recorded $\gamma$ at 3200 of $\mathrm{NH}_{2}$, while that of 7 showed both $=\mathrm{NH}$ and $\mathrm{NH}$ at $\gamma 3362$ and $3160 \mathrm{~cm}^{-1}$. Compounds 6 and 7 showed $\gamma$ at 3038, 3060 for aromatic $\mathrm{CH}$ and $\gamma$ at 2927, 2286 for aliphatic $\mathrm{CH}$ and $\gamma$ at 1580 , 1581 for $\mathrm{C}=\mathrm{N}$, and $\gamma$ at 1341, 1321 for symmetric and asymmetric $\mathrm{NO}_{2}$, and $\gamma$ at 782, 746 for C-F bands. Also compound 6 showed $\gamma$ at 1128 for $\mathrm{C}=\mathrm{S}$.

Additionally, the IR spectrum of both compounds 9 and 11 was recorded $\gamma$ at 2220 for $\mathrm{CN}(9)$ and $\gamma$ at $3363,1694 \mathrm{~cm}^{-1}$ for $\mathrm{OH}$ and $\mathrm{C}=\mathrm{O}$ functional groups 


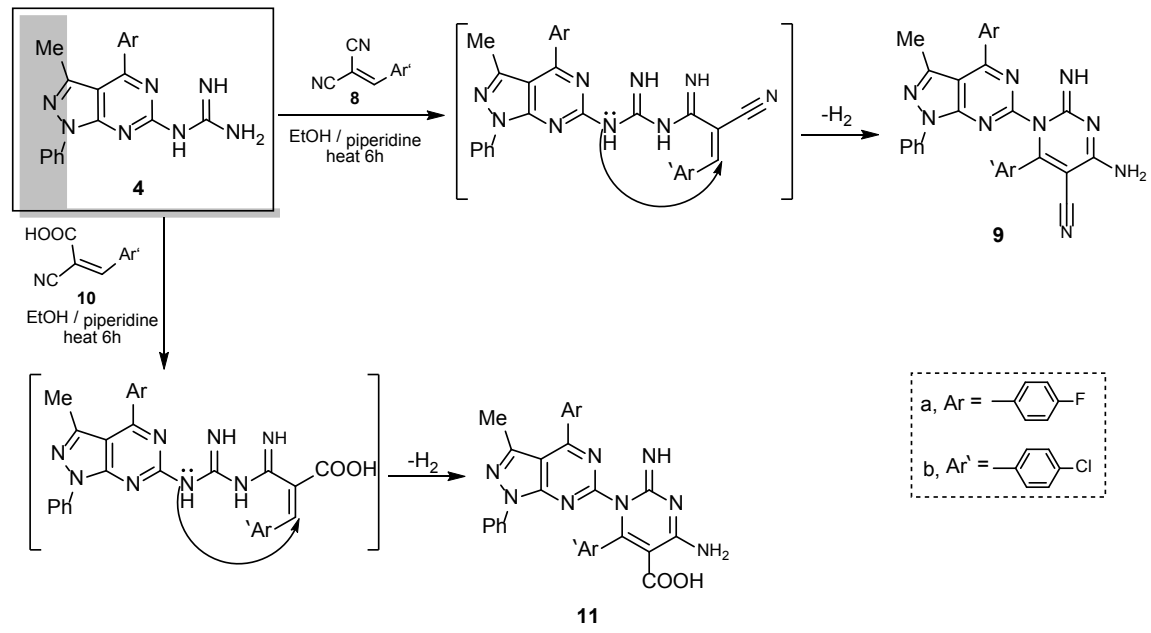

Scheme 3. Synthesis of compounds 9 and 11.

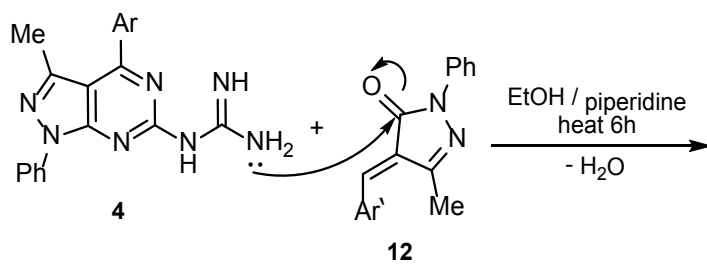

12

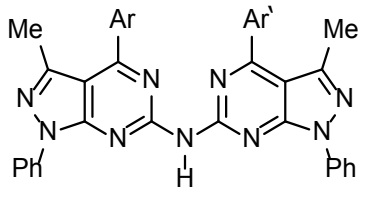

13

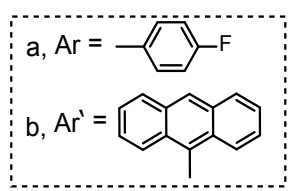

Scheme 4. Synthesis of compound 13.
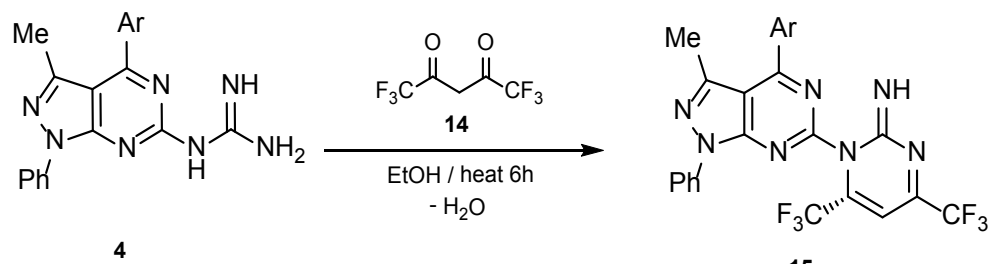

15

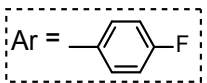

Scheme 5. Synthesis of compound 15.

(11) with the presence the functional of $=\mathrm{NH}, \mathrm{NH}_{2}, \mathrm{C}-\mathrm{F}$, while compound 13 showed only $=\mathrm{NH}$ at $\gamma 3227 \mathrm{~cm}^{-1}$ with lacks of both $\mathrm{C}=\mathrm{O}, \mathrm{NH}_{2}$ and $\mathrm{C}=\mathrm{C}$, which confirm the cycloaddition reaction. As expected, Compound 15 showed $\gamma 3320$ of $=\mathrm{NH}$ with lacks of both $\mathrm{NH}_{2}$ and $\mathrm{C}=\mathrm{O}$ functional groups. Similarly, all the synthesized compounds showed $\gamma$ characterized for aryl aliphatic, $\mathrm{C}=\mathrm{N}$, and $\mathrm{C}-\mathrm{F}$ functional groups.

Furthermore, ${ }^{1} \mathrm{H}$ NMR spectrum of compound 6 showed a resonated signal at $\delta 3.5 \mathrm{ppm}$ for $\mathrm{NH}_{2}$, while that of 7 recorded at $\delta 10.55$ and $8.5 \mathrm{ppm}$ for $=\mathrm{NH}$ and $\mathrm{NH}$ proton compounds 9 and 11 attributed to $=\mathrm{NH}$ and $\mathrm{NH}$ protons, showed slight changed recordings at $\delta 10.55$ and $11 \mathrm{ppm}$ for $=\mathrm{NH}$ and showed at $\delta 3.5$ 
and 3.25 ppm respectively for $\mathrm{NH}_{2}$, although 11 exhibit a resonated signal at $\delta$ $9.5 \mathrm{ppm}$ for $\mathrm{OH}$.

On the other hand, ${ }^{1} \mathrm{H}$ NMR spectra of compounds 13 and 15 showed only one $=\mathrm{NH}$ protons at approximately 11.0 and $10.50 \mathrm{ppm}$.

Focused on function group ${ }^{13} \mathrm{C}$ NMR spectra of compounds 6 and 7 showed at $\delta 182-185$ ppm respectively for $\mathrm{C}=\mathrm{S}$ carbons, while that of 9 and 11 exhibits $\delta$ at 150 and $162 \mathrm{ppm}$ for $\mathrm{CN}$ and $\mathrm{C}=\mathrm{O}$.

All the ${ }^{13}$ CNMR spectra showed also, $\delta$ at $145-143,140,132-122$ and $35-30$ ppm for $\mathrm{C}-\mathrm{F}, \mathrm{C}=\mathrm{N}$, aryl and methyl carbons.

Finally, mass spectral study of some isolated heterobicyclic nitrogen systems reported a $\mathrm{M}^{+}$with the two major bulky fragments which undergo farther fragmentation gave the selected base peak at m/e 95 as 4-fluorophenyl ion (11 and 15) (Figure 1 and Figure 2).
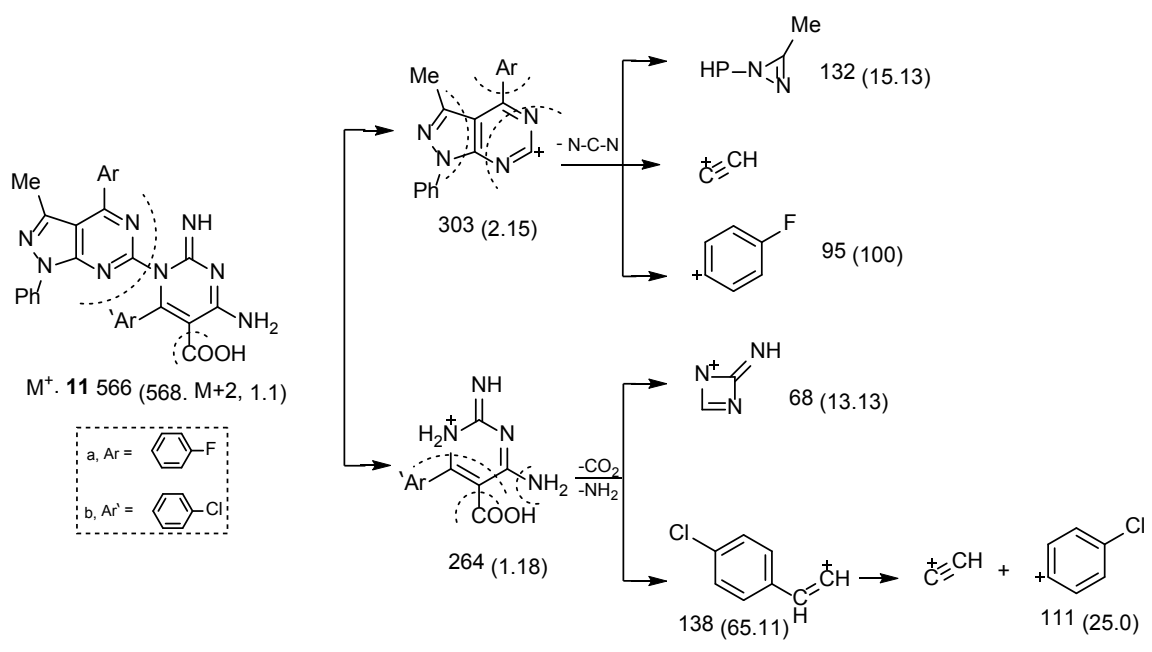

Figure 1. Mass fragmentation pattern of compound 11.
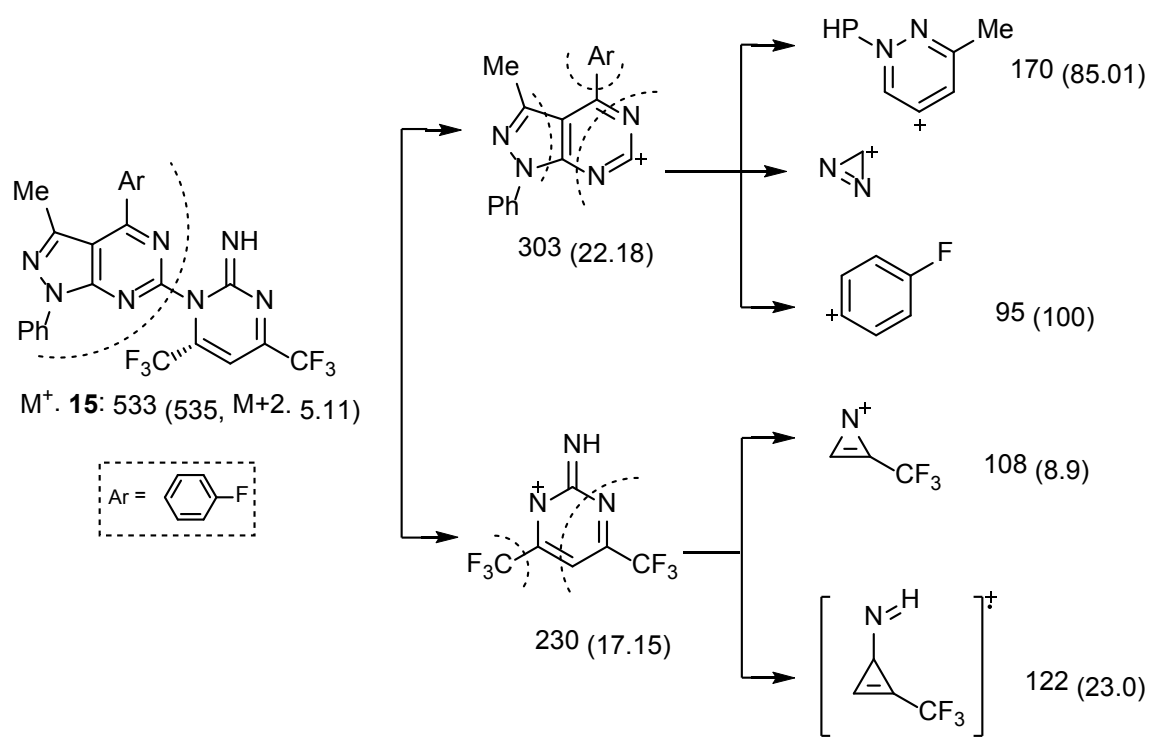

Figure 2. Mass fragmentation pattern of compound 15. 


\section{Antifungal Activity (Cellobiase)}

Due to the medicinal, pharmacological and biological properties of fluorine bearing fused heterobicyclic nitrogen systems the present word tends to evaluate the new fluorine substituted heterobicyclic nitrogen systems as enzymatic affects on the cellobiase produced by fungi [21] [22] [23]. The in vitro antifungal activity of the new fluorinated systems obtained via inhibition of mycelial growth of Penicillium italicum, Helimenthosporiumsatium, Pythium deberyanum and $\mathrm{Fu}$ sarium solani in methanol and sterile potato dextrose agar (PDA) [23].

The fungi toxic activity of the synthesis compounds are tested on P. italium. A Discs of orange rinds $(3 \times 3 \mathrm{~cm})$ were removed from orange fruits. The discs were further sterilized by $70 \%$ ethanol, the rinds were treated with the tested compounds. The treated discs were allowed to dry and were artificially inoculated with spots of P. Itlaicum. The Commercial thiobendazol-2-(4-thiazolyl) benzimidazole (TBZ) Figure 3 was used as control.

The result percentage of rotted discs were evaluated after one weeks Table 1.

Prevention of blue mold development the action of new fluorinated systems obtained on the decay control on rind discs is present in Table 2. The results indicate that only compound $\mathbf{1 5}$ gave good result in comparison with control. On the other hand, compounds which had the same higher $\mathrm{ED}_{50}$ values did not prevent the decay at all concentration used.

Table 1. Antifungal activity of new fluorinated systems toxicity index.

\begin{tabular}{ccccc}
\hline \multirow{2}{*}{ Compound No. } & \multicolumn{4}{c}{ Fungi name ${ }^{\mathrm{a}} \mathrm{ED}_{50}\left(\mu \mathrm{g} \cdot \mathrm{cm}^{-1}\right)$} \\
\cline { 2 - 5 } & $P$. italicum & H. sativum & P. deberyanum & F. solani \\
\hline 6 & $5-10$ & $10-20$ & $50-100$ & $20-50$ \\
7 & $10-20$ & $10-20$ & 100 & 100 \\
9 & 5 & $10-20$ & $50-100$ & $5-10$ \\
11 & 5 & $5-10$ & 5 & 5 \\
13 & $50-100$ & 100 & 100 & $50-100$ \\
15 & 5 & 5 & 5 & 5
\end{tabular}

${ }^{\mathrm{a}} \mathrm{ED}_{50}$ for inhibition of mycellal growth expressed.

Table 2. Effect of new fluorinated pyrimidine on prevention of disease development on rinddiscs.

\begin{tabular}{cccc}
\hline \multirow{2}{*}{ Compound No. } & \multicolumn{2}{c}{ Percentage of decayed discs at different Conc. $\left(\mu \mathrm{g} \cdot \mathrm{cm}^{-1}\right)$} \\
\cline { 2 - 4 } & 100 & 1000 & 4000 \\
\hline 6 & 90.0 & 76.0 & 76.0 \\
7 & 90.0 & 78.0 & 70.0 \\
9 & 80.0 & 76.0 & 40.0 \\
11 & 76.0 & 60.0 & 40.0 \\
13 & 100 & 100 & 100 \\
15 & 20.0 & 10.0 & 0.0 \\
TBZ & 20 & 0.0 & 0.0 \\
\hline
\end{tabular}




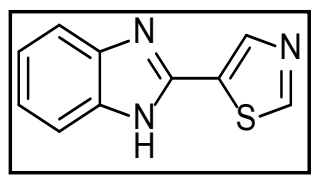

Figure 3. 2-(4'-Thiazolyl) benzimidazole.

According to the Table 1 and Table 2 we suggest the following conclusion:

- The antifungal activity of tested compounds based on $\mathrm{ED}_{50}$ are $15>11>9>$ $6,7>13$.

- Compound 15 gave a good activity in comparison with control TEZ especially at $4000 \mu \mathrm{g} \cdot \mathrm{ml}^{-1}$ may be due to the higher effect of $\mathrm{CF}_{3}$ groups on the biologically sensitivity of tested fungi.

- The compounds which had the same or higher $\mathrm{ED}_{50}$ values did not prevent the decay at all the concentrations used.

\section{Conclusion}

In conclusion, this study provides a short and reasonable low cost route to performance $N$-substituted guanidine towards some $\alpha, \beta, \gamma$-polyfunctional reagents in different conditions to contribute fused heteropolycyclic nitrogen systems as antifungal probes. These compounds have been tasted as antifungal activity, which showed the compounds had the same higher $\mathrm{ED}_{50}$ values did not prevent the decay at all concentration used. The compound 15 has a rich F-atoms exhibited a highly antifungal activity in comparison with control Thiobendazole (TBZ) which can be effective on fungal disease in orange tree.

\section{Experimental}

Melting points determined by an electrochermal Bibly Sturat Scientific melting point sample (UK). A Perkin Elmer Model RXI-FT IR system 55,529 used for IR spectra of the prepared compounds $\left(\mathrm{cm}^{-1}\right)$. A Bruker advance DPX $400 \mathrm{MHZ}$ model uses TMS as internal standard was used for recording the ${ }^{1} \mathrm{H}$ and ${ }^{13} \mathrm{C}$ NMR spectra of the compounds on deuterated DMSO-d6 (ppm). Elemental analysis was performed in micro analytical Center of Cairo University, Cairo, Egypt.

The common organic reagents 5, 8, 10 and 12 were obtained according to the reported methods [11] [12]. Only compound 5 produced from reflux of ammonium thiocyanate with 4-nitrobenzoyl chloride in dry acetone 4-(4'-Fluorobenzylidene)-1-phenyl-3-methyl-pyrazol-5-one (2) and 6-amaino-4-(4'-Fluorophenyl)1-phenyl-3-methyl-pyrazolo[3,4-d]pyrimidine (3) were obtained according the reported method [17].

1-(1'-phenyl-3'-methyl-4'-(4"-fluorophenyl)-pyrazolo [3,4-d] pyrimidine6'-yl)-2-amino-6-(4'-nitrophenyl)-1,3,5-triazin-4-thione (6).

A mixture of $4(0.01 \mathrm{~mol})$ and $5(0.01 \mathrm{~mol})$ in dry dioxane $(100 \mathrm{ml})$ refluxed for $6 \mathrm{~h}$, cooled. The solid obtained filtered off and crystallized from dioxane to give 6 as yellowish crystals. 
Yield 68\% m.p. $>350{ }^{\circ} \mathrm{C}$. IR $(\gamma) \mathrm{cm}^{-1}: 3200(\mathrm{NH} 2), 3038$ (aromatic CH). 2927, 2888 (aliphatic $\mathrm{CH}), 1612(\mathrm{C}=\mathrm{C}), 1580(\mathrm{C}=\mathrm{N}), 1341\left(\mathrm{NO}_{2}\right), 1474,1457$ (bending $\mathrm{CH}_{3}$ ), 1158 (C=S), 1211 (C-F), 861, 820 (substituted aryl), 782 (C-F). ${ }^{1} \mathrm{H}$ NMR (DMSO-d $\left.{ }_{6}\right) \delta$ ppm: 8.4, 8.2 and 8.0, 7.8 (each dd, $\mathrm{CH}-\mathrm{F}$ and $\mathrm{CH}-\mathrm{NO}_{2}$ ), 7.6-7.35, 7.2 - 6.91 (each $\mathrm{m}, 9 \mathrm{H}$, aromatic $\mathrm{CH}), 3.55\left(\mathrm{~s}, \mathrm{NH}_{2}\right), 1.50\left(\mathrm{~s}, 3 \mathrm{H}, \mathrm{CH}_{3}\right) .{ }^{13} \mathrm{C} \mathrm{NMR}$ $\left(\mathrm{DMSO}_{6} \mathrm{~d}_{6} \delta\right.$ ppm: $182(\mathrm{C}=\mathrm{S}), 145(\mathrm{C}-\mathrm{F}), 142(\mathrm{C}=\mathrm{N}), 138\left(\mathrm{C}-\mathrm{NO}_{2}\right), 130-122$ (aromatic carbons), 38 (C- $\mathrm{CH}_{3}$ carbon). Aral. Calcd.; C, 58.58\%; H, 3.64\%; F, $3.43 \%$; N, 22.77\%; S, 5.79\% for $\mathrm{C}_{27} \mathrm{H}_{18} \mathrm{~N}_{9} \mathrm{FSO}_{2}$ (553). Found: C, 58.49\%; H, 3.22\%; F, 3.21\%; N, 22.61\%; S, 5.50\%.

1-(1'-phenyl-3'-methyl-4'-fluorophenyl-pyrazolo[3,4-d]pyrimidine-6'-yl)-2 -imino -4-(4'-nitrophenyl)-1,3,5-triazin-6 (SH) thione (7).

Equimolar mixture of 4 and ' 5 in ethanol $(100 \mathrm{ml})$ with drops of piperidone refluxed for $6 \mathrm{~h}$, cooled then adds drops of acetic acid. The produced solid, filtered off and crystalized from dioxane to give 7 as yellowish crystals.

Yield 75\%, m.p. $>340^{\circ} \mathrm{C}$. IR $(\gamma) \mathrm{cm}^{-1}: 3362(=\mathrm{NH}), 3160(\mathrm{NH}), 3060$ (aromatic $\mathrm{CH}), 2886$ (aliphatic $\mathrm{CH}), 1603(\mathrm{C}=\mathrm{C}), 1581(\mathrm{C}=\mathrm{N}), 1321\left(\mathrm{NO}_{2}\right), 1271(\mathrm{C}-\mathrm{F})$, 879, 849 (substituted phenyl), 746 (C-F). ${ }^{1} \mathrm{H}$ NMR (DMSO-d 6 ) $\delta$ ppm: $10-55$ $(=\mathrm{NH}), 8.5(\mathrm{NH}), 8.4,8.25,8.0,7.95$ (each d.d $\mathrm{CH}-\mathrm{F}$ and $\mathrm{CH}-\mathrm{NO}_{2}$ ). $7.80-7.66$, 7.45 - 6.95 (each m, 9H, aromatic $\mathrm{CH}$ ), $1.2\left(\mathrm{~s}, \mathrm{CH}_{3}\right) \cdot{ }^{13} \mathrm{C}$ NMR $\left(\mathrm{DMSO}_{6} \mathrm{~d}_{6}\right) \delta$ ppm: $185(\mathrm{C}=\mathrm{S}), 148(\mathrm{C}-\mathrm{F}), 146(\mathrm{C}=\mathrm{N}), 140(\mathrm{C}-\mathrm{N}), 135\left(\mathrm{C}-\mathrm{NO}_{2}\right), 130-124$ (aromatic carbons), $34\left(\mathrm{C}-\mathrm{CH}_{3}\right)$. Aral. Calcd.; C, 58.80\%; H, 3.29\%; F, 3.44\%; N, $22.86 \%$; S, 5.81\% for $\mathrm{C}_{27} \mathrm{H}_{18} \mathrm{~N}_{9} \mathrm{FSO}_{2}$ (551). Found: C, 58.65\%; H, 3.08\%; F, 3.19\%; N, 22.51\%; S, 5.55\%.

1-(1'-phenyl-3'-methyl-4'-(4"-fluorophenyl)-pyrazolo[3,4-d]pyrimidine-6'yl)-2-imino-4-amino-6-(4'-chlorophenyl)-pyrimidine-5-yl-carbonitrile (9).

A mixture of $4(0.01 \mathrm{~mol})$ and $8(0.01 \mathrm{~mol})$ in EtOH $(100 \mathrm{ml})$ with drops of piperidine refluxed for $6 \mathrm{~h}$, cooled then poured onto ice. The solid resulted, filtered off and crystalized from EtOH to give 9 as deep brown crystals.

Yield 65\%, m.p. > $330{ }^{\circ} \mathrm{C}$. IR $(\gamma) \mathrm{cm}^{-1}: 3350(=\mathrm{NH}), 3150\left(\mathrm{NH}_{2}\right), 2220(\mathrm{C \Xi H})$, $1607(\mathrm{C}=\mathrm{C}), 1449$ (bending $\mathrm{CH}_{3}$ ), $1254(\mathrm{C}-\mathrm{F}), 968,880,798$ (substituted phenyl), 752 (C-F), 650 (C-Cl). ${ }^{1} \mathrm{H}$ NMR (DMSO-d 6 ) $\delta$ ppm: 10.55 (s, =NH), 8.2, 8.0, 7.8, 7.75 (each d.d CH-F and $\mathrm{CH}-\mathrm{Cl}$ ), 7.66 - 7.40, 7.2 - 6.85 (each $\mathrm{m}, 9 \mathrm{H}$, aromatic $\mathrm{CH}), 3.5$ (s, 2H, $\mathrm{NH}_{2}$ ), 1.25 (s, 3H, Me). ${ }^{13} \mathrm{C} \mathrm{NMR}$ (DMSO-d $\left.{ }_{6}\right) \delta$ ppm: $150(\mathrm{CN})$, $147(\mathrm{C}-\mathrm{F}), 142(\mathrm{C}=\mathrm{N}), 140(\mathrm{C}-\mathrm{Cl}), 132-121$ (aromatic carbons), $35\left(\mathrm{C}-\mathrm{CH}_{3}\right.$ carbon). Aral. Calcd.; C, 63.56\%; H, 3.50\%; Cl, 6.47\%; F, 3.47\%; N, 23.00\% for $\mathrm{C}_{29} \mathrm{H}_{19} \mathrm{~N}_{9} \mathrm{FCl}$ (547). Found: C, 63.41\%; H, 3.29\%; Cl, 6.25\%; F, 3.31\%; N, 22.89\%.

1-(1'-phenyl-3'-methyl-4'-(4"-fluorophenyl)-pyrazolo[3,4-d] pyrimidine6'-yl)-2-imino-4-amino-6-(4'-chlorophenyl)-pyrimidine-5-carboxylic acid (11).

A mixture of $4(0.01 \mathrm{~mol})$ and $10(0.01 \mathrm{~mol})$ in EtOH $(100 \mathrm{ml})$ with drops of piperidine refluxed for $6 \mathrm{~h}$, cooled then poured onto ice. The solid produced filtered off and crystalized from dioxane to give 11 as deep brown crystals.

Yield 60\%, m.p. $198^{\circ} \mathrm{C}-200^{\circ} \mathrm{C}$. IR $(\gamma) \mathrm{cm}^{-1}: 3363(\mathrm{OH}), 3300(=\mathrm{NH}), 3150$ $\left(\mathrm{NH}_{2}\right), 2888$ (aliphatic $\left.\mathrm{CH}_{3}\right), 1694(\mathrm{C}=\mathrm{O}), 1609(\mathrm{C}=\mathrm{C}), 1585(\mathrm{C}=\mathrm{N}), 1490$ 
(bending $\mathrm{CH}_{3}$ ), 1272 (C-F), 940, 879, 859 (substituted phenyl), 746 (C-F), 609 $(\mathrm{C}-\mathrm{Cl}) .{ }^{1} \mathrm{H}$ NMR (DMSO-d ${ }_{6}$ ) $\delta$ ppm: $11(\mathrm{~s},=\mathrm{NH}), 9.5(\mathrm{~s}, 1 \mathrm{H}, \mathrm{OH}), 8,9(\mathrm{~s}, 1 \mathrm{H}$, $\mathrm{NH}$ ), 8.4, 8.2 and 7.9, 7.7 (each d.d CH-F and $\mathrm{CH}-\mathrm{Cl}$ ), 7.5 - 7.25, and $7.1-6.8$ (each m, 9H, aromatic $\mathrm{CH}$ ), $3.25\left(\mathrm{~s}, 2 \mathrm{H}, \mathrm{NH}_{2}\right), 1.25$ (s, 3H, Me). ${ }^{13} \mathrm{C} \mathrm{NMR}$ $\left(\right.$ DMSO- $\left._{6}\right) \delta$ ppm: $162(\mathrm{C}=\mathrm{O}), 145(\mathrm{C}-\mathrm{F}), 142(\mathrm{C}=\mathrm{N}), 139\left(\mathrm{C}-\mathrm{NO}_{2}\right), 131-123$ (aromatic carbons), $39\left(\mathrm{C}-\mathrm{CH}_{3}\right.$ carbon). $\mathrm{M} / \mathrm{S}(\mathrm{m} / \mathrm{e}, \mathrm{Int} \%)=568(\mathrm{M}+2,1.1)$, 303 (2.15), 264 (1.18), 138 (65.11), 132 (15.13), 111 (25.0), 95 (100), 68 (13.13). Aral. Calcd.; C, 61.43\%; H, 3.56\%; Cl, 6.25\%; F, 3.35\%; N, $19.76 \%$ for $\mathrm{C}_{29} \mathrm{H}_{2} \mathrm{ON}_{8} \mathrm{FClO}_{2}$ (566). Found: C, 61.31\%; H, 3.41\%; Cl, 5.91\%; F, 3.15\%; N, 19.59\%.

1-(1'-phenyl-3'-methyl-4'-(4"-fluorophenyl)-pyrazolo[3,4-d]pyrimidine-6'yl)-2-imino-4-methyl-6-phenyl-7-(anthracen-9'-yl)-pyrimido[5,4-d]pyrazol e (13).

Equimolar mixture of 4 and 12 in EtOH $(100 \mathrm{ml})$ with drops of piperidine refluxed for $6 \mathrm{~h}$, cooled then poured onto ice. The yielded solid, filtered off and crystalized from dioxane to give 13 as deep violet crystals.

Yield $72 \%$, m.p. $170^{\circ} \mathrm{C}-172^{\circ} \mathrm{C}$. IR $(\gamma) \mathrm{cm}^{-1}$ : $3227(=\mathrm{NH}), 3060$ (aromatic $\mathrm{CH}$ ), 2880 (aliphatic $\mathrm{CH}), 1609(\mathrm{C}=\mathrm{C}), 1250(\mathrm{C}=\mathrm{N}), 1453$ (bending $\left.\mathrm{CH}_{3}\right), 1224(\mathrm{C}-\mathrm{F})$, 908, 850, 800 (substituted phenyl), 752 (C-F), 600 (C-Cl). ${ }^{1} \mathrm{H}$ NMR (DMSO-d $\mathrm{d}_{6}$ ) $\delta$ ppm: $11(\mathrm{~s}, 1 \mathrm{H},=\mathrm{NH}), 8.4,8.11$ and 8.0, 7.88 (each d.d CH-F and $\mathrm{C}_{2} \mathrm{H}$ and $\mathrm{C}_{8} \mathrm{H}$ of anthracene), 7.7 - 7.41, 7.2 - 6.9, 6.6 - 6.4 (each $\mathrm{m}, 18 \mathrm{H}$, aromatic protons). 1.45 and 1.25 (each s, $2 \mathrm{CH}_{3}$, protons). ${ }^{13} \mathrm{C}$ NMR (DMSO-d ${ }_{6}$ ) $\delta$ ppm: $145(\mathrm{C}-\mathrm{F})$, $142(\mathrm{C}=\mathrm{N}), 138(\mathrm{C}=\mathrm{C}), 132-124$ (aromatic $\mathrm{CH}), 40$ and $36\left(2 \mathrm{CH}_{3}\right.$ carbon). Aral. Calcd.; C, 75.09\%; H, 4.30\%; F, 2.70\%; N, 17.91\% for $\mathrm{C}_{44} \mathrm{H}_{30} \mathrm{~N}_{9} \mathrm{~F}$ (703). Found: C, $74.91 \%$; H, 4.11\%; F, 2.22\%; N, 17.75\%.

1-(1'-phenyl-3'-methyl-4'-(4'-fluorophenyl)-pyrazolo[3,4-d]pyrimidine-6'yl)-2-imino-4,6-di(trifluoromethyl) pyrimidine (15).

A mixture of $4(0.01 \mathrm{~mol})$ and $14(0.01 \mathrm{~mol})$ in $\mathrm{EtOH}(50 \mathrm{ml})$ with drops of piperidine refluxed for $2 \mathrm{~h}$, cooled then poured onto ice. The yielded solid, filtered off and crystalized from $\mathrm{MeOH}$ to give $\mathbf{1 5}$ as yellowish crystals.

Yield 78\%, m.p. > 350 ${ }^{\circ} \mathrm{C}$. IR $(\gamma) \mathrm{cm}^{-1}: 3320(=\mathrm{NH}), 3039$ (aromatic CH), 2887 (aliphatic $\mathrm{CH}), 1612(\mathrm{C}=\mathrm{C}), 1598(\mathrm{C}=\mathrm{N}), 1474,1447$ (bending $\left.\mathrm{CH}_{3}\right), 1211(\mathrm{C}-\mathrm{F})$, 907, 861, 822, 783 (substituted phenyl), 750 (C-F), 721 (C-F), 695 (C-F). ${ }^{1} \mathrm{H}$ NMR (DMSO-d $\left.{ }_{6}\right) \delta$ ppm: $10.5(\mathrm{~s}, 1 \mathrm{H},=\mathrm{NH}), 8.9\left(\mathrm{~d} .1 \mathrm{H}, \mathrm{C}_{5}-\mathrm{H}\right.$ of hexafluoromethyl pyrimidine), 8.2, 8.0 (d. CH-F), 7.7 - 7.4, 7.2 - 6.88 (each m, $9 \mathrm{H}$, aromatic protons), 1.25 (s, $\left.3 \mathrm{H}, \mathrm{CH}_{3}\right) .{ }^{13} \mathrm{C} \mathrm{NMR}\left(\mathrm{DMSO}_{-} \mathrm{d}_{6}\right) \delta \mathrm{ppm:} 148(=\mathrm{NH}), 144(\mathrm{C}-\mathrm{F})$, $140(\mathrm{C}-\mathrm{N}), 130-124(\operatorname{aromatic} \mathrm{CH}), 40\left(\mathrm{C}-\mathrm{CH}_{3}\right.$ carbon). M/S (m/e, Int. \%) = 535 (M + 2, 5.11), 303 (55.18), 230 (17.15), 170 (85.01), 122 (23.0), 108 (8.90), 95 (100). Aral. Calcd.; C, 54.04\%; H, 2.65\%; F, 24.93\%; N, $18.38 \%$ for $\mathrm{C}_{24} \mathrm{H}_{14} \mathrm{~N}_{7} \mathrm{~F}_{7}$ (533). Found: C, 53.89\%; H, 2.41\%; F, 24.65\%; N, 18.59\%.

\section{Acknowledgements}

The authors would like to thank the Chemistry Department at King Abdulaziz University, Jeddah, for supporting this Research. Thanks to Prof Reda Abdel- 
Rahman (D.Sc. Organic chemistry), for his help and constant support.

\section{Conflicts of Interest}

The authors declare no conflicts of interest regarding the publication of this paper.

\section{References}

[1] Abdul-Rahman, R., Bakhotmah, D. and Fakhorji, M. (2017) Synthesis and Chemical Reactivity of Some New Fluorine Substituted Pyrazolopyrimidine Derivatives and Their Effect on Cellobiase Activity Produced by Fungi. World Journal of Organic Chemistry, 5, 1-5. http://pubs.sciepub.com/wjoc/5/1/1

[2] Bakhotmah, D., Abdel-Rahman, R., Fakhrji, M. and kamal, A. (2017) Synthesis of Some New Fluorinated Fused Heteropolycyclic Nitrogen Systems Containing Pyrazolo[3,4-d]pyrimidines Moiety and Their Effects on Cellobiase Activity Produced by Aspergillusnidulans Fungi. Modern Organic Chemistry, 2, 172-178.

[3] Bakhotmah, D. and Abdel-Rahman, R. (2017) Synthesis and Structural Determination of Novel Fluorinated Steroidal Spiro(pyrazolo[4,3-e][1,2,4]triazin-3'-yl) Derivatives as Affecting Enzymatic Agents. Letters in Organic Chemistry, 14, 134-140. https://doi.org/10.2174/1570178614666161230143228

[4] Shamroukh, A.H., Rashad, A.E., Ali, H.S. and Abdel-Megeid, F.M.E. (2013) Some New Pyrazole and Pyrazolopyrimidines: Synthesis and Antimicrobial Evaluation. Journal of Heterocyclic Chemistry, 50, 758-765. https://doi.org/10.1002/jhet.1550

[5] Bakavoli, M., Bagherzadeh, G., Vaseghifar, M., Shiri, A., Pordel, M., Mashreghi, M., Pordeli, P. and Araghi, M. (2010) Molecular Iodine Promoted Synthesis of New Pyrazolo[3,4-d]pyrimidine Derivatives as Potential Antibacterial Agents. European Journal of Medicinal Chemistry, 45, 647-650. https://doi.org/10.1016/j.ejmech.2009.10.051

[6] Yuan, L., Song, C., Li, C., Li, Y., Dong, L. and Yin, S. (2013) Synthesis and Biological Evaluation of Pyrazolo[4,3-d]pyrimidine Analogues. European Journal of Medicinal Chemistry, 67, 152-157. https://doi.org/10.1016/j.ejmech.2013.05.019

[7] Shamroukh, A.H., Rashad, A.E., Abdel-Megeid, R.E., Ali, H.S. and Ali, M.M. (2014) Some Pyrazole and Pyrazolo[3,4-d]pyrimidine Derivatives: Synthesis and Anticancer Evaluation. Archiv der Pharmazie, 347, 559-565. https://doi.org/10.1002/ardp.201400064

[8] Ismail, F.M.D. (2002) Important Fluorinated Drugs in Experimental and Clinical Use. Journal of Fluorine Chemistry, 118, 27-33. https://doi.org/10.1016/S0022-1139(02)00201-4

[9] Ojima, I., McCarthy, J.R. and Welch, J.T. (1996) Biomedical Frontiers of Fluorine Chemistry. American Chemical Society, 639, 372. https://doi.org/10.1021/bk-1996-0639

[10] Abdel-Rahman, R., Makki, M.S.T., Ali, T.E.-S. and Ibrahim, M.A. (2010) 1,2,4-Triazine Chemistry Part I: Orientation of Cyclization Reactions of Functionalized 1,2,4-Triazine Derivatives. European Journal of Chemistry, 1, 236-245. https://doi.org/10.1021/bk-1996-0639

[11] Abdel-Rahman, R. and Abdel-Monem, W. (2007) Chemical Reactivity of 3-Hydrazino-5,6-diphenyl-1,2,4-triazine towards Pi-Acceptors Activated Carbonitriles. Indian Journal of Chemistry, 46, 838-846.

[12] Abdel-Monem, W. and Abdel-Rahman, R. (2006) Synthesis of 3-Heteroaryl-6,7- 
diphenyl-1,2,4-triazo-lo[4, 3-b] [1,2,4]tria-zines and Their Biological Activities. International Journal of Chemistry, 16, 1-14.

[13] Ibrahim, M., Abdel-Rahman, R., Abdel-Halim, A., Ibrahim, S. and Allimony, H. (2009) Synthesis, Chemical Reactivity and Fungicidal Activity of Pyrido[1,2-b] [1,2,4] triazine derivatives. Journal of the Brazilian Chemical Society, 20, 1275-1286. https://doi.org/10.1590/S0103-50532009000700012

[14] Ibrahim, M., Abdel-Rahman, R., Abdel-Halim, A., Ibrahim, S. and Allimony, H. (2008) Synthesis and Antifungal Activity of Novel Polyheterocyclic Compounds Containing Fused 1,2,4-Triazine Moiety. Arkivoc, 16, 202-215.

[15] Makki, M., Bakhotmah, D., Abdel-Rahman, R. and Aqlan, F. (2018) New Route to Synthesize Fluorine Substituted Lamotrigine Drug Analogues as an Anti-Inflammatory Agent. Current Organic Synthesis, 15, 116-125.

https://doi.org/10.2174/1570179414666170509151123

[16] Khan, S.A., Asiri, A.M., Abdel-Rahman, R., Elroby, S.A., Aqlan, F.M.S., Wani, M.Y. and Sharma, K. (2017) Multistep Synthesis of Fluorine-Substituted Pyrazolopyrimidine Derivatives with Higher Antibacterial Efficacy Based on in Vitro Molecular Docking and Density Functional Theory. Journal of Heterocyclic Chemistry, 54, 3099-3107. https://doi.org/10.1002/jhet.2923

[17] Bakhotmah, D. (2019) Synthesis and Chemical Reactivity of 6-amino-4-(4'-fluorophenyl)-1-phenyl-3-methyl-pyrazolo[3,4-d]pyrimidine towards Some Activated Electophiles and Their Effect on Cellobiase Activity Produced by Some Fungi.

[18] Munoz-Torrero, D., Mangoni, A.A., Guillou, C., Collina, S., VandenEynde, J.J., Rautio, J., Keseru, G.M., Hulme, C., Chibale, K., Luque, F.J., Karaman, R., Gutschow, M., Liu, H. and Ragno, R. (2017) Breakthroughs in Medicinal Chemistry: New Targets and Mechanisms, New Drugs, New Hopes. Molecules, 22, pii: E743.

[19] Júnior, P.E.S., Rezende, L.C.D., Gimenes, J.P., Maltarollo, V.G., Dale, J., Trossini, G.H.G., Emery, F.S. and Ganesan, A. (2016) Synthesis of Two "Heteroaromatic Rings of the Future" for Applications in Medicinal Chemistry. RSC Advances, 6, 22777-22780. https://doi.org/10.1039/C6RA01099G

[20] Bakhotmah, D. and Abdel-Rahman, R. (2016) A Review on the Synthesis and Chemistry of Bioactive Pyrazolines Bearing 1,2,4-Triazine Moieties. Mini-Reviews in Organic Chemistry, 13, 62-77. https://doi.org/10.2174/1570193X13666160225000114

[21] Fang, X.J., Jeyakkumar, P., Avula, S.R., Zhou, Q. and Zhou, C.H. (2016) Design, Synthesis and Biological Evaluation of 5-Fluorouracil-Derived Benzimidazoles as Novel Type of Potential Antimicrobial Agents. Bioorganic \& Medicinal Chemistry Letters, 26, 2584-2588. https://doi.org/10.1016/j.bmcl.2016.04.036

[22] Ryu, J.H., Lee, J.A., Kim, S., Shin, Y.A., Yang, J., Han, H.Y., Son, H.J., Kim, Y.H., Sa, J.H., Kim, J.-S., Lee, J., Lee, J. and Park, H.-G. (2016) Discovery of 2-((R)-4-(2-Fluoro-4-(methylsulfonyl)phenyl)-2-methylpiperazin-1-yl)-N-((1R,2s,3S,5S,7S)-5-hydro xyadamantan-2-yl)pyrimidine-4-carboxamide (SKI2852): A Highly Potent, Selective, and Orally Bioavailable Inhibitor of $11 \beta$-Hydroxysteroid Dehydrogenase Type 1 (11 $\beta$-HSD1). Journal of Medicinal Chemistry, 59, 10176-10189. https://doi.org/10.1021/acs.jmedchem.6b01122

[23] Chamberlain, K. and Carter, G.A. (1980) The Fungitoxicity of Substituted 2-Phenylbenzofurans. Pesticide Science, 11, 526-532. https://doi.org/10.1002/ps.2780110510 